\title{
Exploration of the Theoretical Physical Capacity of the John F. Kennedy International Airport Runway System
}

\author{
Kurt W. Neitzke* \\ NASA Langley Research Center, Hampton, VA, 23681-2199 \\ and \\ Nelson M. Guerreiro ${ }^{\dagger}$ \\ NASA Langley Research Center, Hampton, VA, 23681-2199
}

\begin{abstract}
:
A design study was completed to explore the theoretical physical capacity (TPC) of the John F. Kennedy International Airport (KJFK) runway system for a northflow configuration assuming impedance-free (to throughput) air traffic control functionality. Individual runways were modeled using an agent-based, airspace simulation tool, the Airspace Concept Evaluation System (ACES), with all runways conducting both departures and arrivals on a first-come first-served (FCFS) scheduling basis. A realistic future flight schedule was expanded to 3.5 times the traffic level of a selected baseline day, September 26, 2006, to provide a steady overdemand state for KJFK runways. Rules constraining departure and arrival operations were defined to reflect physical limits beyond which safe operations could no longer be assumed. Safety buffers to account for all sources of operational variability were not included in the TPC estimate. Visual approaches were assumed for all arrivals to minimize inter-arrival spacing. Parallel runway operations were assumed to be independent based on lateral spacing distances. Resulting time intervals between successive airport operations were primarily constrained by same-runway and then by intersecting-runway spacing requirements. The resulting physical runway capacity approximates a theoretical limit that cannot be exceeded without modifying runway interaction assumptions. Comparison with current KJFK operational limits for a north-flow runway configuration indicates a substantial throughput gap of approximately $48 \%$. This gap may be further analyzed to determine which part may be feasibly bridged through the deployment of advanced systems and procedures, and which part cannot, because it is either impossible or not cost-effective to control. Advanced systems for bridging the throughput gap may be conceptualized and simulated using this same experimental setup to estimate the level of gap closure achieved.
\end{abstract}

\section{Nomenclature}

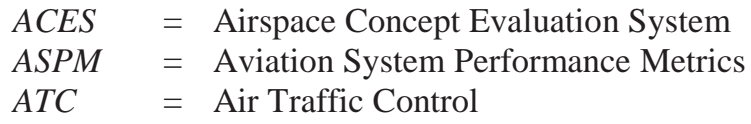

\footnotetext{
* Senior Research Engineer, Aeronautics Systems Analysis Branch, Mail Stop 442, member AIAA.
}

$\dagger$ Research Engineer, Crew Systems and Aviation Operations Branch, Mail Stop 152, member AIAA. 


$\begin{array}{ll}C D \& R & =\text { Conflict Detection \& Resolution } \\ D H & =\text { Decision Height } \\ E T M S & =\text { Enhanced Traffic Management System } \\ F C F S & =\text { First come first served } \\ G C R & =\text { Great Circle Route } \\ H A T & =\text { Height Above Terrain } \\ \text { KJFK } & =\text { John F. Kennedy International Airport } \\ \text { LAHSO } & =\text { Land And Hold Short Operations } \\ \text { LUAW } & =\text { Line Up and Wait } \\ \text { N/A } & =\text { Not Applicable } \\ \text { NAS } & =\text { National Airspace System } \\ n m & =\text { Nautical Mile } \\ P R M & =\text { Precision Runway Monitor } \\ R \& D & =\text { Research \& Development } \\ R O T & =\text { Runway Occupancy Time } \\ T O F L & =\text { Take Off Field Length } \\ T P C & =\text { Theoretical Physical Capacity } \\ T S A M & =\text { Transportation Systems Analysis Model } \\ V M C & =\text { Visual Meteorological Conditions }\end{array}$

\section{Introduction}

$\mathrm{U}$ nderstanding the theoretical physical capacity (TPC) of the John F. Kennedy International Airport (KJFK) runway system, subject to operational assumptions, enables comparison with current KJFK throughput capacities found in the Aviation System Performance Metrics (ASPM) data archive. Differences between current capacities and the TPC represent a throughput gap that results - in part - from an inability to accurately and precisely synchronize trajectories to achieve minimum safe spacing intervals at runways for arrival and departure operations. This inability is partly due to air traffic control (ATC) functionality that safely separates airborne and surface traffic, and adds spacing buffers to account for variability between actual and forecast trajectory positions and times. Knowledge of the size of the gap between current, actual runway-system throughput and the TPC will enable research and development (R\&D) organizations to assess whether closing this gap appears feasible from a favorable cost/benefit ratio perspective. Given that it is deemed feasible, the amount of throughput gap closure achieved by deploying new advanced concepts and/or procedures may be estimated using simulation tools such as the Airspace Concept Evaluation System (ACES). The physical capacity analysis described here initially focuses on the airport runways because they represent a true, single-degree-of-freedom (in-trail spacing interval) traffic flow constraint. Elsewhere along a given flight's gate-to-gate trajectory, routing around constrained National Airspace System (NAS) resources (both surface and airborne) is typically a physical option.

Two primary design spaces for increasing runway capacity may be considered: one that considers design options within the assumed operational constraints and a second that modifies those assumptions. Understanding the operational constraint assumptions underlying the TPC estimate, allows advanced airspace systems concept and procedure developers to assess whether the assumed constraints would be expected to endure in the future, or whether some might be relaxed or eliminated through the deployment of targeted, advanced concepts or procedures. For the later design space, concept and procedure developers may modify the constraints assumptions to reflect alternative views of their feasible, future values, and then show the sensitivity of the TPC estimate to those modification(s). Although this type of physical constraints assessment begins with airport runway systems, it can be extended similarly to each of the other airspace domains corresponding to the various segments of gate-to-gate flight trajectories (e.g., departure, cruise, arrival, etc.). Comparing current capacities with TPCs for each domain should reveal those posessing the largest throughput gaps. Likewise, comparing TPCs across all flight domains should reveal those with the lowest values, where one might expect NAS traffic flow to choke or saturate initially. This, in turn, might suggest where system development priorities might be focused to realize the greatest NAS capacity increases.

Several sources in the research literature document the maximum capacity of airport runway systems, including KJFK. Some sources estimate maximum capacity at an aggregate level for each runway, or for the entire airport, based upon stochastic representations of aircraft arrival and departure demand by weight classification. Other studies explore individual runway or airport average capacity limits based upon representative mixes of aircraft weight 
classes operating at the airport. Still other sources collect actual arrival and departure data at individual runways and fit statistical models to the data. These statistical models may then be used by subsequent research studies to represent aggregate operational demand. These approaches ${ }^{1-6}$ tend to randomize the order of arrival and departure demand by weight class, rather than using historical, as-flown air traffic data which would include any business objcetives that may be reflected in the actual order of operation by weight class. To the author's knowledge, this study represents the first attempt to directly estimate the TPC using agent based simulation, on an operation-by-operation basis using a realistic future flight schedule, while accounting for the effects of weight classification and order of operation to individual runways at KJFK. With this approach, aggregate levels of runway and airport throughput are represented by a simple summation of successive individual runway operations over a given time span.

\section{Experiment Approach}

Using ACES to directly simulate each runway operation requires defining same-runway and intersecting-runway operational constraints in the form of required time-interval spacing between successive airport operations. For air traffic arriving to, and departing from an airport, several spacing constraints must be satisfied (some concurrently) including radar, wake vortex, runway occupancy and jet blast for example. The largest spacing requirement among them becomes the binding constraint between successive airport operations and - over time - determines the throughput capacity of the airport runway system. Constraints on successive runway operations at KJFK were initially defined by current operational rules per DOT/FAA JO 7110.65U: Air Traffic Control. Some rules therein were modified based on research literature suggesting feasible future limits that are less capacity constraining ${ }^{7-10}$, while remaining sufficiently safe. Similarly, current operating practices such as independent parallel runway operations to runway spacing as low as 3,000 feet, with precision runway monitoring (PRM), offset localizer, and monitor controllers in place, were assumed for this study regardless of whether presently deployed at JFK. Visual approaches were assumed for all arrivals, and corresponding spacing intervals used within ACES. The reasoning underlying these assumptions was to conceptually maximize the runway system's capacity using all currently available systems and procedures that appear feasibly deployable at KJFK, together with new system improvements that appear headed for near-term future NAS deployment. Additional capacity may only then be achieved by deploying new advanced systems and procedures. Given these operational constraints, the TPC of the KJFK runway system in a north-flow configuration with runways 31L, 31R, 04L, and 04R conducting mixed arrival and departure operations was estimated using ACES. Capacities for the airport surface - exclusive of runways - and for terminal airspace surrounding KJFK were assumed to be infinite (i.e., fully impedance-free to throughput), such that the TPC of the runway system alone could be estimated. No conflict detection and resolution (CD\&R) was conducted for terminal airspace traffic, and was instead left to future studies.

A runway-modeled version of the KJFK airport, rather than the more common nodal source/sink airport representation, was required within the ACES simulation tool to estimate the TPC. The KJFK runway system is shown in Fig. 1 for reference. Airport throughput (i.e., all runways) in ACES is determined by the most constraining value among the applicable runway interaction and spacing tables for the type of consecutive operation pair under consideration. Consecutive operation pairs are as follows: arrival followed by arrival (ARR-ARR), arrival followed by departure (ARR-DEP), departure followed by arrival (DEP-ARR), or departure followed by departure (DEP-DEP). Spacing table values represent the minimum required time interval (in seconds) between consecutive operations on either the same runway or on one of the intersecting runways. Average aircraft speeds - by weight class - were used

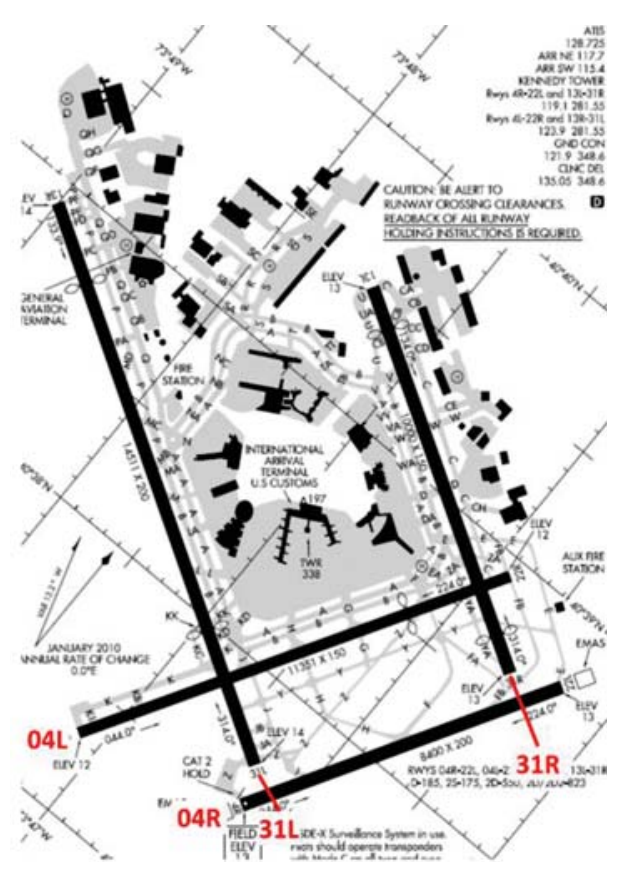

Figure 1. KJFK airport runways: $04 \mathrm{~L}, 04 \mathrm{R}, 31 \mathrm{~L}$, and 31R (Source - Federal Aviation Administration) 
in determining the spacing intervals listed, and an example spacing table for runway $31 \mathrm{~L}$ is provided in Table 1 . In the table, the first operation (i.e., "LEADER") of each consecutive operational pair is on 31L followed by the second operation (i.e., "FOLLOWER") on each interacting runway (i.e., either the same or intersecting runway). Parallel runways were assumed to operate independently because spacing between $31 \mathrm{~L}$ and $31 \mathrm{R}$ exceeds 4,300 feet, and spacing between 04L and 04R is 3,000 feet with PRM and other monitoring assumed, as discussed previously.

Table 1. Sample: Runway 31L ACES Interaction/Spacing Table

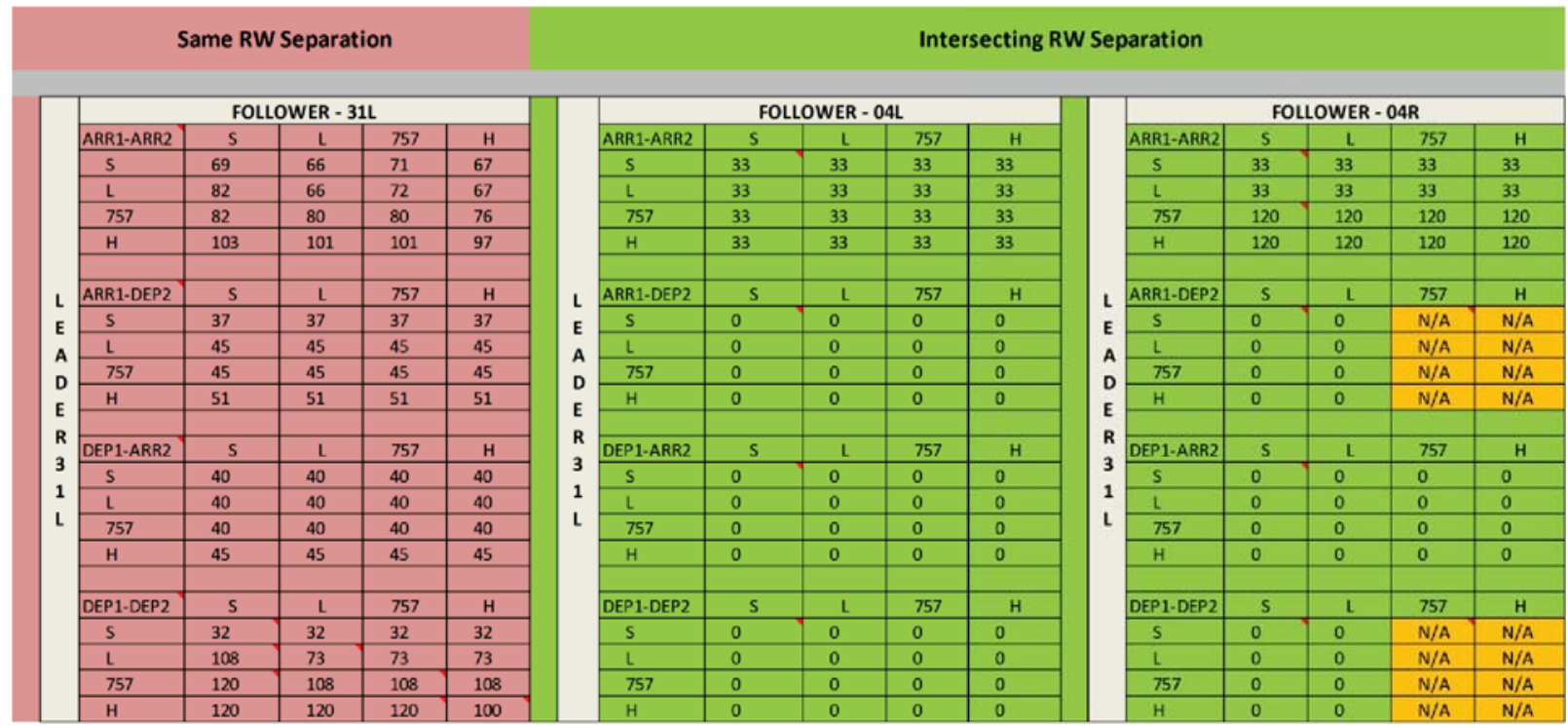

Operational assumptions that determine the time intervals shown in Table 1 are listed in Table 2.

Table 2. Runway 31L Spacing Interval Operational Assumptions

\begin{tabular}{|c|c|c|c|}
\hline $\begin{array}{ll}\mathrm{RW}-1 \\
31 \mathrm{LW}\end{array}$ & $\begin{array}{c}31 \mathrm{~L} \\
\text { (Same RW) }\end{array}$ & $\begin{array}{c}04 \mathrm{~L} \\
\text { (Intersecting RW) }\end{array}$ & $\begin{array}{c}04 \mathrm{R} \\
\text { (Intersecting RW) }\end{array}$ \\
\hline ARR/ARR & $\begin{array}{l}\text { Based on the lowest same- } \\
\text { runway inter-arrival time } \\
\text { intervals from Refs. 9, 12, and } \\
13\end{array}$ & $\begin{array}{l}\text { 31L ARR clear of intersection prior } \\
\text { to 04L ARR at twice the decision } \\
\text { height }(\mathrm{DH})(\mathrm{DH}=200 \mathrm{ft} \text { height } \\
\text { above terrain (HAT)) or } 400 \mathrm{ft}, \\
\text { along a 3-deg glide slope at an } \\
\text { approach speed of } 140 \mathrm{kt} \\
\text { - Assumes 04L ARR touches down } \\
\text { prior to 31L intersection }(3,700+\mathrm{ft} \\
\text { to intersection) }\end{array}$ & $\begin{array}{l}\text { - 31L ARR clear of intersection prior to } \\
\text { 04R ARR at twice the DH along 3-deg } \\
\text { glide slope at approach speed of } 140 \mathrm{kt} \\
\text { 7110.65U; Fig. 3-10-10; wake } \\
\text { turbulence constraint (NOTE: } \\
\text { Assumes wake turbulence not a } \\
\text { constraint for small or large weight } \\
\text { class lead A/C) }\end{array}$ \\
\hline ARR/DEP & $\begin{array}{l}\text { Based on ROT with } 30 \text { degree } \\
\text { high-speed runway exits from } \\
\text { Ref's:9, } 12 \text { \& } 13\end{array}$ & $\begin{array}{l}\text { 04L DEP commences once 31L } \\
\text { ARR clear of intersection } \\
\left(* * \text { NOTE** 31L displaced }^{* *}\right. \\
\text { threshold beyond } 04 \mathrm{~L} \text { intersection })\end{array}$ & $\begin{array}{ll}\text { - } & \text { 04R Heavy \& B757 departures } \\
\text { prohibited due to runway length } \\
\text { - } \\
\text { 04R Small \& Large departures } \\
\text { commence take-off roll after 31L ARR } \\
\text { crosses over 04R; assumes LUAW }\end{array}$ \\
\hline DEP/ARR & $\begin{array}{l}\text { Based on JO 7110.65U; } \\
\text { departure airborne \& > 6000 } \\
\text { Ft from ARR crossing the } \\
\text { threshold }\end{array}$ & $\begin{array}{l}\text { - Assumes 31L intersection departure } \\
\text { commences beyond 04L } \\
\text { intersection and 04L ARR touches } \\
\text { down prior to 31L intersection (i.e. } \\
\text { - no jet blast constraint) }\end{array}$ & $\begin{array}{l}\text { 31L departures assumed to begin } \\
\text { beyond 04L intersection, therefore jet } \\
\text { blast is not a constraint }\end{array}$ \\
\hline DEP/DEP & $\begin{array}{l}\text { Based on JO 7110.65U; } \\
\text { requires } 2 \text { minutes for DEP2 } \\
\text { following } 757 / \text { Hvy, but use } \\
\text { radar separation per 5-5-4 for } \\
\text { all cases when required } \\
\text { interval is less than } 2 \text { min. } \\
\text { (assumes LUAW \& } \\
\text { Anticipating Separation) }\end{array}$ & $\begin{array}{l}\text { - Assumes 31L intersection departure } \\
\text { commences beyond 04L } \\
\text { intersection and 04L DEP not } \\
\text { airborne prior to 31L intersection } \\
\text { (i.e. - Jet Blast not a constraint) }\end{array}$ & $\begin{array}{l}\text { Assume 04R Heavy \& B757 } \\
\text { departures prohibited due to RW } \\
\text { length } \\
\text { 31L departures assumed to begin } \\
\text { beyond 04L intersection, therefore jet } \\
\text { blast is not a constraint }\end{array}$ \\
\hline
\end{tabular}


The shorter runway lengths of $31 \mathrm{R}$ and $04 \mathrm{R}$ were assumed to prohibit certain types of departure operations (denoted by "N/A" in the interaction tables). Runway $31 \mathrm{R}$ was assumed to be unsuitable for heavy class departures, although it is likely that the runway is used for a number of these types of departures in actual practice. This assumption is based on the fact that approximately 62 percent of heavy operations at KJFK in 2010 were international flights $^{11}$, and heavy class takeoff field length (TOFL) requirements at maximum takeoff weight routinely exceed the 10,000-ft runway length of 31R. Aircraft departures in the B757 weight class were assumed to operate from 31R, although certain variants require greater than the 10,000-ft TOFL available. This assumption is based on the fact that approximately 75 percent of B757 operations at KJFK are domestic flights and thus, are not likely to be at maximum takeoff weight. Also, only about one-third of the worldwide B757 fleet requires greater than a 10,000-ft TOFL at maximum takeoff weight. Both B757 and heavy class departures were prohibited on runway 04R due to its 8,400-ft length. Similar to heavy class departures on 31R, some actual B757 departures likely use 04R, with some corresponding change to the estimated TPC observed in this study. Runway 31L departures were assumed to begin beyond the 04L intersection (i.e., intersection take-offs). This eliminated any intersecting-runway interactions between 31L departures and all 04L operations. All other runways were assumed to use their full length for departures. Jet blast from departures on runways 31L and 31R were considered as potential constraints upon operations on runways 04L and 04R. After further detailed assessment of the six potential interaction scenarios however, they were assumed to not constrain those operations. Land and hold short operations (LAHSO) were assumed for arrivals on runways 04L and 04R, thereby removing most of the corresponding interactions with 31R. All arrivals to 04L were assumed to land and hold short of 31R, while all but heavy class arrivals to 04R were assumed to do the same.

An existing ACES runway scheduler, employing both planning and freeze time horizons in its scheduling process, was modified for use in this study. Each flight enters a planning horizon at 34 minutes prior to its unimpeded arrival or departure time to or from a default-assigned (by ACES) KJFK runway. Unimpeded times refer to trajectories flown without delay due to weather, traffic, or any other source. At 30 minutes prior to the unimpeded arrival or departure time, the flight crosses a freeze horizon where a final runway assignment is given. At each one minute simulation time cycle, the ACES scheduler plans, on a trial basis, all flights that are within their respective planning horizons (i.e., between 34 and 30 min from their unimpeded arrival or departure time). The number of flights within the ACES scheduling window varies with each simulation time cycle due to new aircraft entering and others exiting their respective planning horizons. Within each scheduler planning cycle, the current runway assignment and runway arrival or departure time for each flight is compared with each of the other available runway options. Employing firstcome first-served (FCFS) principles, the scheduler iterates over each feasible runway assignment to find the earliest (in simulation time) time slot for the last operation among all of the flights being planned. The algorithm that achieves the maximum throughput is the one that compresses the planned group of operations the most, while satisfying the runway interaction and spacing table constraints. Within this FCFS scheduling paradigm, no overarching arrival or departure priority is applied to the airport traffic demand.

\section{Experiment Design}

\section{A. Flight schedule generation}

The flight schedule used by ACES was based on the high volume, low adverse weather, baseline day of September $26^{\text {th }} 2006$ using ETMS flight track data. 2006 was the most recent data available for this study, from a standard set of flight schedules developed for NASA's Airspace Systems Program. The baseline traffic was expanded using the Transportation Systems Analysis Model (TSAM) ${ }^{\S}$ to a level of KJFK arrival/departure demand in excess of the TPC. This was to ensure that queues of arrival and departure flights were always present to fill an available runway slot at the earliest time allowed by the runway spacing tables. The flight schedule simulated in ACES was nominally 3.5 times the baseline day traffic level (i.e. 1,065 flights per 24 hours in 2006, and 3,773 flights per 24 hours for this study).

\footnotetext{
‡ Airplane characteristics for airport planning: Boeing: http://www.boeing.com/commercial/airports/plan manuals.html; Airbus: http://www.airbus.com/support/airport-operations/library/.

$\S$ TSAM developed by The Air Transportation Systems Laboratory at Virginia Polytechnic Institute and State University; www.atsl.cee.vt.edu/tsam.htm
} 


\section{B. ACES simulation}

As stated previously, ACES was configured to simulate operations to runways 31L \& R and 04L \& R with each runway conducting mixed arrival \& departure operations on a FCFS basis. It was hypothesized that mixed operations on each runway would result in the highest combined airport capacity. Dedicated arrival \& departure fixes were defined for each runway end. Arrival fixes were located at 6 and $9.5 \mathrm{~nm}$ from their respective runway thresholds. These distances allowed for greater than 1,000-ft vertical separation, and greater than a 3-nm lateral separation along a 3-degree glide slope for arrival aircraft to turn onto its final approach course without loss of separation, as shown in Fig. 2. Similarly, departure fixes were located at 4 and $7.5 \mathrm{~nm}$ from their departure thresholds. Structured routings to/from the arrival/departure fixes were not used and great circle routes (GCRs) were instead simulated in ACES. Wind effects on flight trajectories were not modeled, and CD\&R was not performed by ACES for this experiment, and both were left to future studies to determine whether the terminal airspace adjacent to KJFK can transact the arrival and departure traffic - at runway TPC levels - without excessive conflicts or losses of separation.

On the ground, capacity is also assumed to be infinite for this study. Evaluating the ability of the surface movement system to transact taxiin/out operations at runway TPC levels was also left to future studies. The runway TPC estimated here provides the design TPC requirement for both the surrounding terminal airspace and the surface domains to match, under the same assumed operational conditions. These requirements should be useful to new system/procedure developers in considering

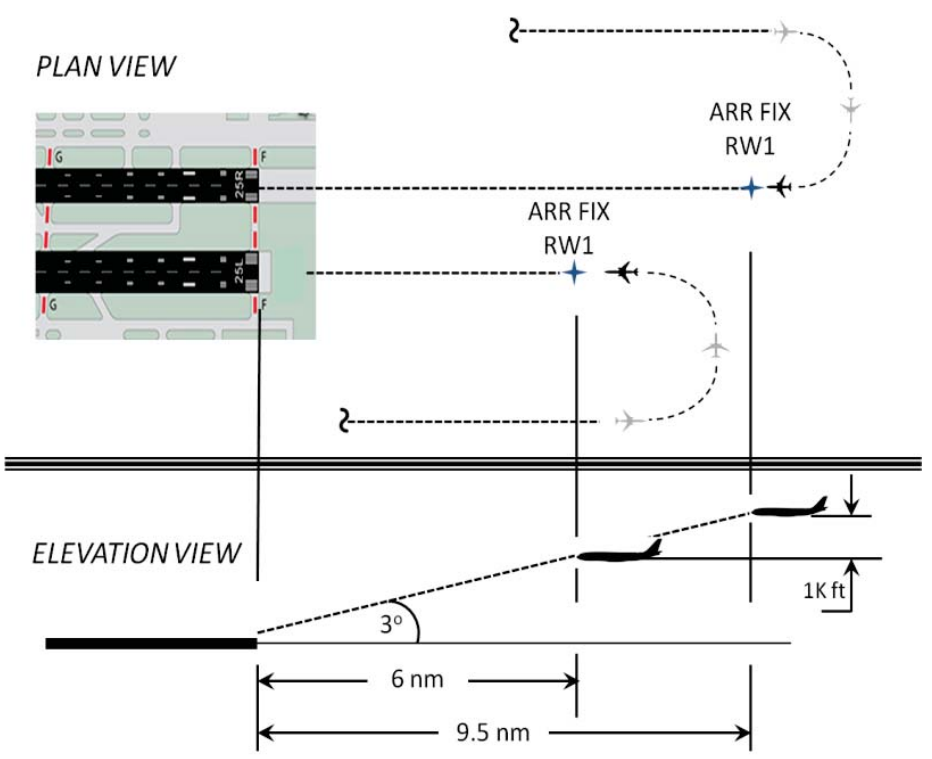

Figure 2. Vertical Separation During Turn Onto Final Approach various design options for increasing NAS throughput in those operational domains. In like manner, this approach may be extended to each domain along a typical gate-to-gate flight to impedance-match the entire NAS.

\section{Results}

Results are provided for seven test cases that comprise five different runway use configurations. The nominal case consists of runways 31L, 31R, 04L, and 04R conducting mixed departure and arrival operations; six additional configurations were simulated for comparison. A 4-hr unimpeded time period was simulated, during which unimpeded arrival and departure operations (i.e., 951 flights) provided the steady over-demand state required for this study. Case one was the nominal case; expected to provide the maximum KJFK throughput among those analyzed. Case two was the configuration with the fewest intersecting-runway interactions, based on inspection of the ACES runway interaction tables. Case three represented the north flow configuration with the highest operational capacity (i.e., 112 operations per hr) listed in the ASPM data archive for calendar year 2010. Case four was the same as case three, except that mixed arrival and departure operations were permitted on runways 31L and 31R. Case five was based on the preferred runway configuration that resulted when an arrivals-only scenario, then a departures-only scenario were separately simulated in ACES, with all runways accepting both arrivals and departures. The preferred runways emerged when ACES scheduled only three of the four available runways for each scenario. For the arrivals-only and departures-only scenarios, one runway (31R for departures-only and 31L for arrivals-only) had a higher degree of constraining interactions compared with the other three runway options. Consequently, virtually no operations were scheduled to those runways because they were never the throughput maximizing option. Case six was run to verify that the TPC results for case one did not substantially change (i.e., the results represented the true physical limit) with a further increase in traffic demand. Here, a 3-hour (reduced from 4-hour scenarios for the other cases due to ACES computation time) unimpeded traffic sample was doubled by duplicating the original flights and uniformly distributing the new operations within a +/- 15-min range of their respective original departure times, for 
a total of 1,262 flights. Finally, case 7 investigated the TPC effects of increasing all runway spacing intervals by 50 percent. Table 3 lists each of the seven test cases.

\begin{tabular}{|c|l|l|l|}
\hline $\begin{array}{c}\text { Case } \\
\text { No. }\end{array}$ & \multicolumn{1}{|c|}{$\begin{array}{c}\text { Arrival } \\
\text { Runways }\end{array}$} & $\begin{array}{c}\text { Departure } \\
\text { Runways }\end{array}$ & \multicolumn{1}{c|}{ Description } \\
\hline \hline 1 & 04L\&R-31L\&R & 04L\&R-31L\&R & Nominal Case; expected highest throughput level \\
\hline 2 & 04L\&R-31R & 31L\&R & Fewest runway interactions \\
\hline 3 & $31 \mathrm{~L} \& \mathrm{R}$ & $31 \mathrm{~L}$ & $\begin{array}{l}\text { ASPM most frequent north flow configuration and highest } \\
\text { operational rate for 2010 }\end{array}$ \\
\hline 4 & $31 \mathrm{~L} \& \mathrm{R}$ & $31 \mathrm{~L} \& \mathrm{R}$ & Same as Case 3 except add 31R departures \\
\hline 5 & 04L\&R-31R & 04L\&R-31L & $\begin{array}{l}\text { Configuration resulting from the ACES runway scheduler - for an } \\
\text { arrivals-only and a departures-only scenario - with all runways } \\
\text { accepting mixed arrival and departure operations }\end{array}$ \\
\hline 6 & 04L\&R-31L\&R & 04L\&R-31L\&R & Double the nominal case traffic; Compare with Case 1 \\
\hline 7 & 04L\&R-31L\&R & 04L\&R-31L\&R & 1.5x Spacing Intervals; Compare with Case 1 \\
\hline
\end{tabular}

\section{Table 3, Runway Use Cases Assessed}

Results suggest, subject to experimental assumptions, that the TPC for the KJFK runway system has a mean of approximately 41.5 total operations, with a standard deviation of 3.5 operations per quarter-hour time span. This mean operational rate sums to 166 operations per hour, which is substantially higher (a 48.2 percent increase) than the maximum rate of 112 operations per hour that is listed in the ASPM data archive for KJFK in a north-flow configuration with arrivals on 31L and 31R and departures on 31L. Again, the TPC estimate is a theoretical rather than a practical operational limit for KJFK. However, if even half of the indicated throughput gap was feasibly recoverable with a favorable cost/benefit ratio, the effort would certainly be worth undertaking. Table 4 shows the resulting throughput values from each simulated case. The 41.5 operations per 15 -min time interval TPC for KJFK for case 1 appears to be confirmed as a physical limit based on the fact that the double-traffic scenario (case 6) returns approximately the same throughput value.

\begin{tabular}{|c|c|c|}
\hline $\begin{array}{c}\text { Case } \\
\text { No. }\end{array}$ & $\begin{array}{c}\text { Mean Throughput } \\
\text { (Operations per 15 minute Epoch) }\end{array}$ & Standard Deviation \\
\hline \hline 1 & 41.5 & 3.50 \\
\hline 2 & 38.8 & 3.98 \\
\hline 3 & 22.2 & 2.54 \\
\hline 4 & 25.4 & 2.88 \\
\hline 5 & 38.6 & 2.04 \\
\hline 6 & 42.3 & 3.69 \\
\hline 7 & 28.2 & 2.25 \\
\hline
\end{tabular}

Table 4. Average throughput and standard deviations for each simulation run (per 15 minutes).

More detailed results are presented below for case 1, to provide additional insight into the underlying TPC dynamics. Figure 3 shows the binned (15-min bin size) arrivals, departures, and total operations for each runway and for the airport total. The maximum throughput for KJFK in this runway configuration is identified from the total operations plot. 

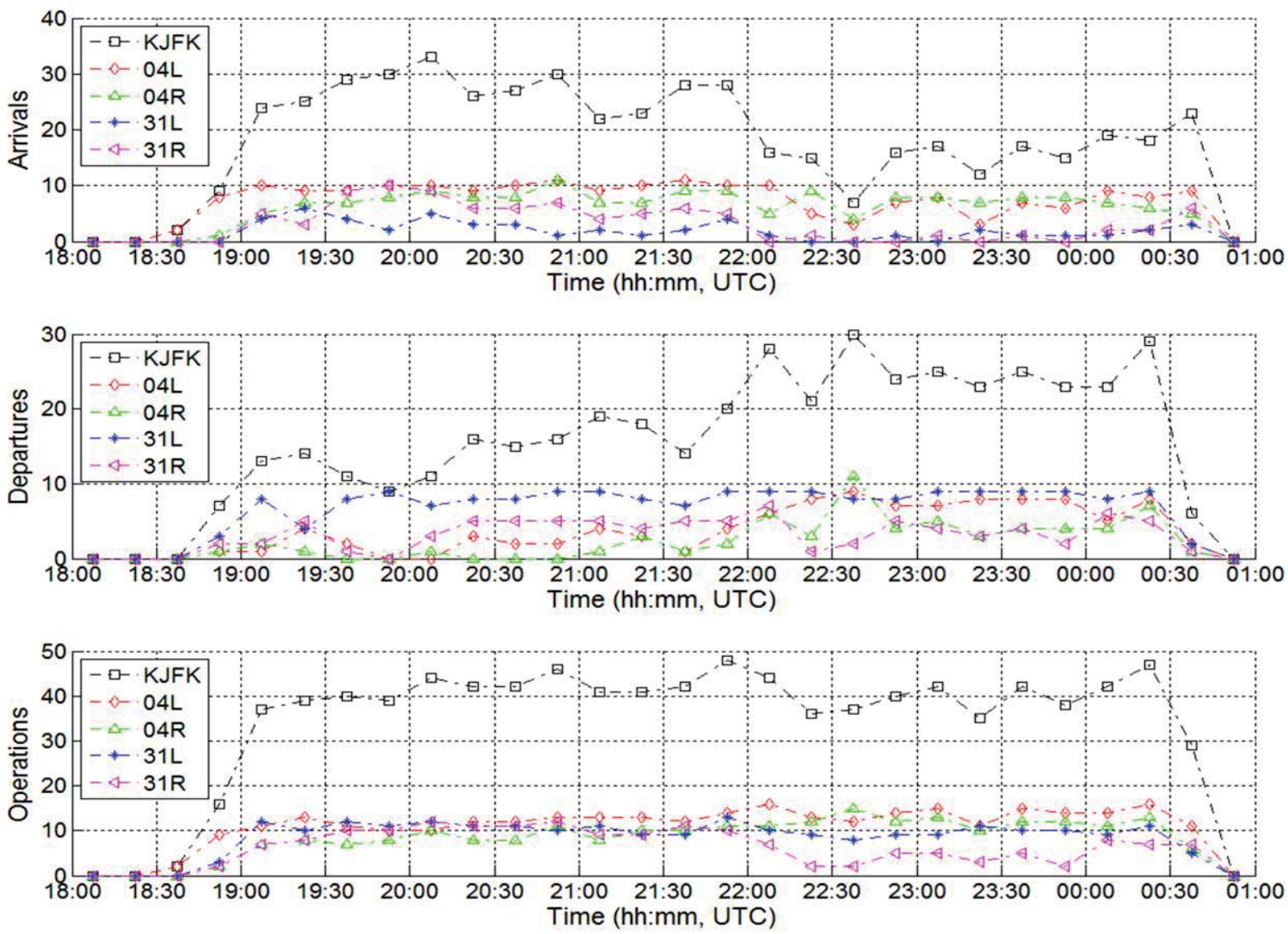

Figure 3. Runway and airport operations by 15-min bin for arrivals (top), departures (middle), and total

Figure 4 shows the delay for each flight as the simulation progresses. This figure clearly shows a steady overdemand state at the airport after 19:30 (i.e., the delay begins to steadily increase through the end of the simulation.) As the simulation nears the end, demand queues empty, and reduced delay levels can be seen as the runway capacity eventually exceeds demand. Two regions of the plot (i.e., from approximately 20:30 to 20:45 and 21:45 to 22:00) indicate short-term periods where the airport capacity exceeded demand and the delay declined accordingly. Although delay declined briefly during those periods, queues of aircraft demand for both arrivals and departures remained such that no available runway slots were left unused. 


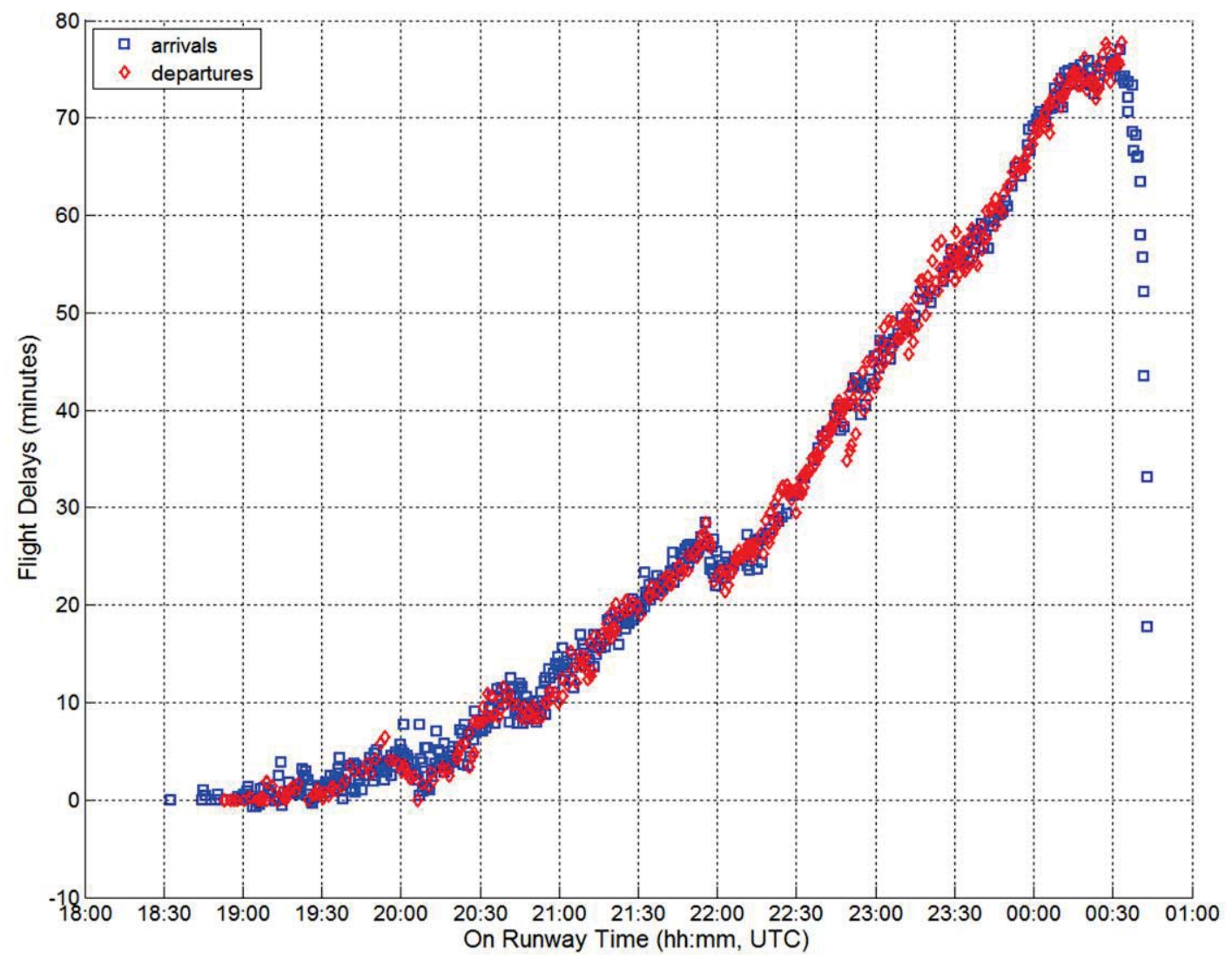

Figure 4. Delay For each flight at simulated runway arrival time

Figure 5 shows the number of successive operations on each runway that fall into the various spacing interval bins. Clear peaks can be seen at intervals which correspond to values listed in either the same-runway, or intersecting-runway spacing tables. Other spacing intervals found in figure 5 result from multiple operation interactions and are consequently not found in the spacing tables. An example would be for three consecutive operations on runway 04L: a heavy departure followed by a heavy arrival, followed by a heavy departure. According to the spacing tables, the required interval between operations one and two is $45 \mathrm{~s}$, while required spacing between operations two and three is 51s for a cumulative spacing of 96s between operations one and three. However, the required spacing between two successive departures from the same runway (i.e. the first and third operations) is 100s from the tables, which is four seconds longer than the 96s cumulative spacing requirement cited above. Consequently, four seconds are added to the required 51s between operations two and three for a total of 55 s, which is the value found in figure 5 , but not in the spacing tables. Finally, some spacing intervals correspond to the beginning and end of the scenario, where demand did not exceed the airport capacity. Consequently, those operations were unimpeded, but at spacing intervals larger than the minimums listed in the spacing tables. 
04L
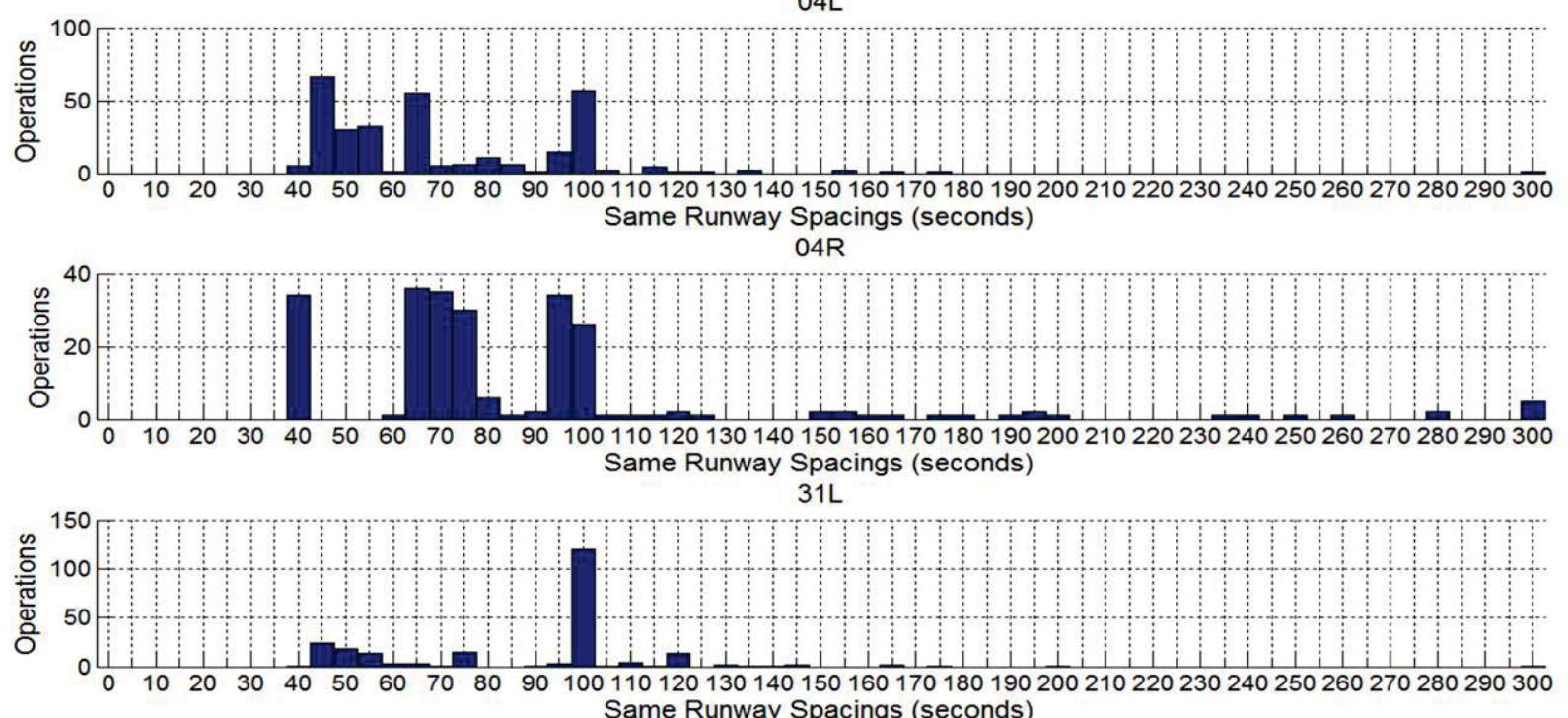

$31 \mathrm{R}$

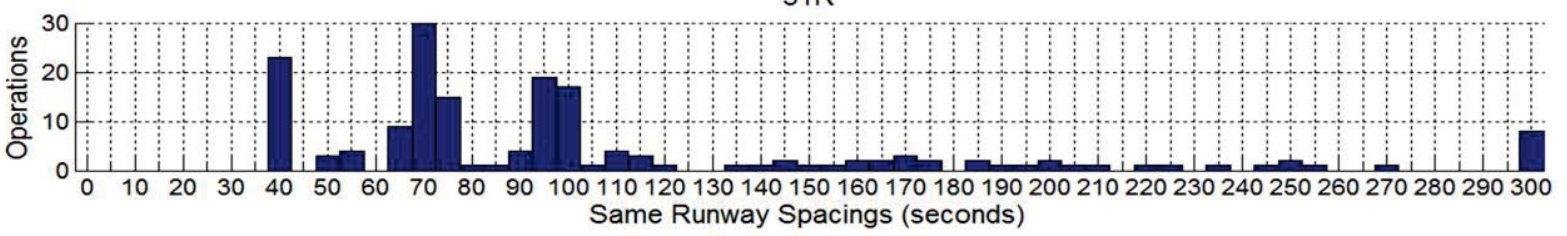

Figure 5. Same runway interoperation spacing (top to bottom: 04L, 04R, 31L, 31R)

Table 5 lists the type, number, and percentage of binding constraints by runway, that determined the KJFK TPC. It is interesting to note that same-runway spacing requirements constrained operations to $04 \mathrm{~L}, 04 \mathrm{R}$ and $31 \mathrm{~L}$ between $85 \%$ and $90 \%$ of the time, whereas intersecting runway spacing requirements constrained operations to 31R almost $43 \%$ of the time. This reflects interaction between the temporal aspect of the arrival/departure schedule by weight class, and the required spacing intervals (that are functions of weight class) listed in the runway interaction tables. Other contributing factors included: heavy class departures being prohibited from 31R due to insufficient length; 04R prohibiting both heavy and B-757 departures similarly; and a high demand for heavy departures - particularly later in the simulated traffic day - which could only be assigned to either $31 \mathrm{~L}$ or $04 \mathrm{~L}$. Total operations on 31R were significantly lower than to the other KJFK runways due to the above interactions as well.

Table 5. Number and Percentage of Binding Throughput Constraints; Same and Other Runway

\begin{tabular}{|l|l|l|l|l|}
\hline Runway & $\begin{array}{l}\text { Same runway } \\
\text { spacing constraints }\end{array}$ & $\begin{array}{l}\text { Other runway } \\
\text { spacing } \\
\text { constraints }\end{array}$ & $\begin{array}{l}\text { Same } \\
\text { runway, } \\
\text { percent }\end{array}$ & Other runway, percent \\
\hline $04 \mathrm{~L}$ & 274 & 31 & 89.8 & 10.2 \\
\hline $04 \mathrm{R}$ & 200 & 35 & 85.1 & 14.9 \\
\hline $31 \mathrm{~L}$ & 201 & 34 & 85.5 & 14.5 \\
\hline $31 \mathrm{R}$ & 100 & 75 & 57.1 & 42.9 \\
\hline
\end{tabular}


Figure 6 shows the simulated (actual) operations versus the unimpeded demand for operations at KJFK. The effects of imposing runway spacing constraints on arrivals and departures can be observed by the reduction in the unimpeded demand peaks (i.e., total (unimp.) plot) to the TPC level (i.e., total (actual) plot). This demand peak reduction resulted in an extension of the time required to process the KJFK runway demand that had queued awaiting available runway slots.

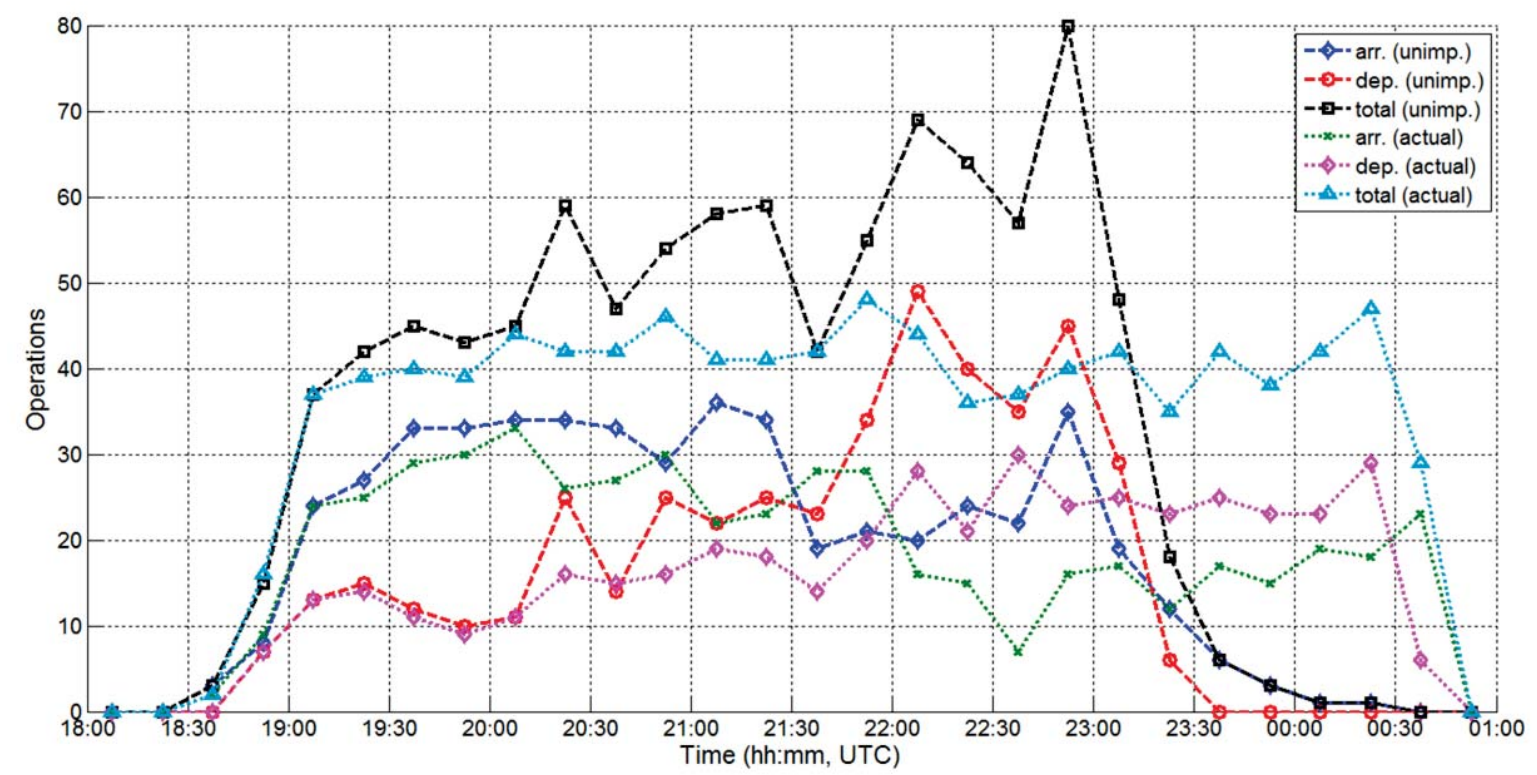

Figure 6. Simulated operations versus unimpeded demand at KJFK

\section{Conclusion}

An estimate of the theoretical physical capacity (TPC) of John F. Kennedy International Airport (KJFK) in a north-flow configuration with runways 31L, 31R, 04L, and 04R conducting mixed arrival and departure operations has been generated by this study. The TPC estimate assumes an ideal operational environment including low winds, visual meteorological conditions (VMC) with all arrivals conducting visual approaches, and full KJFK operational capacity. Although this runway use configuration is not actually employed at $\mathrm{KJFK}^{* *}$ it appears to provide the maximum TPC based on comparison with alternate north-flow runway configurations. The estimated TPC of 166 operations per hour is approximately 48 percent higher than the highest acceptance rate of 112 operations per hour among north-flow runway configurations listed in the Aviation System Performance Metrics (ASPM) data archive.

It is acknowledged that this TPC is not practically achievable because it is based on each operation occurring at precisely the minimum required safe spacing interval as defined in the runway spacing tables used by ACES. Actual operations cannot be performed this precisely due to variability between scheduled versus actual times to complete each of the many discreet operational segments and corresponding functions of gate-to-gate flight trajectories. Some variability may be controlled using well-designed and operationally refined systems and procedures, while some may be inherently difficult or impossible to control. Examples of difficult or impossible to control variability include random, unanticipated events such as aircraft or air traffic control (ATC) system malfunctions, crew unavailability, obstruction by ground equipment, runway closure, various latency sources, and such. Accordingly, the degree of this capacity gap that might be bridged using new systems and procedures is not entirely clear.

This TPC estimate does, however, provide an idealized design target for use, initially by surface-movement and terminal-airspace-movement system developers, in assessing various design options at approaching this idealized throughput level. Variability, both controllable and inherent, may be addressed via the "art" of system design. That is - the variability that is controllable, with a favorable cost/benefit ratio will be addressed in the system design, and that

${ }^{* *}$ Based on a review of runway configurations listed in ASPM for 2010. 
which is either not controllable (i.e., random) or not cost effective to control may be considered inherent. Additional insight into controllable versus inherent variability should be gained as system developers assess the performance of new systems through the conceptual and preliminary design phases.

The robustness of new systems to real-world operational environments should also be addressed in the system development/design cycle. Robust systems design typically strives to achieve the same operational performance level as under pristine operating conditions, while addressing impediments (e.g., winds, weather) that degrade performance. In this manner, the TPC estimate provides a useful performance target for system developers as they design robustness into their systems. This TPC estimate also provides insight regarding the limits to achievable capacity increases in the absence of more foundational and costly measures, such as adding new runways at congested airports or perhaps engaging nearby regional airports to add runway capacity to a congested metroplex environment. Finally, the ACES model used to estimate this TPC, may be used to explore alternative "what-if" scenarios and enable sensitivity assessments that explore how the TPC changes under different operational conditions and assumptions.

Finally, it was cited earlier that the runway configuration which provided the highest TPC for KJFK in this study (i.e. $31 \mathrm{R} \& \mathrm{~L}$ and $04 \mathrm{R} \& \mathrm{~L}$ each conducting mixed arrival and departure operations), is not actually used presently. The reasons for this are unknown to the authors, but are likely due to constraints resulting from nearby airport operations (particularly LaGuardia (LGA) and Newark (EWR)), community noise considerations, airport and airspace adaptations, and the like. Such reasons would typically be documented in airport standard operating procedures, letters of agreement between airport towers and TRACONs, and similar documents. Some of these constraints may not lend themselves to mitigation via deployment of new, advanced traffic management systems. Valuable next steps in analyzing KJFK's TPC would be to review the relevant documents and perhaps visit the KJFK airport tower and New York TRACON facilities to gain a fuller understanding of actual, current, operational constraints to capacity. With this fuller understanding, the constraints assumptions used for this study can be updated accordingly, and a new TPC estimated, along with the throughput gap between TPC and current capacity. The updated constraints may then be reviewed by concept/capability developers to determine those which may be mitigated via deployment of new, advanced traffic management systems and procedures. 


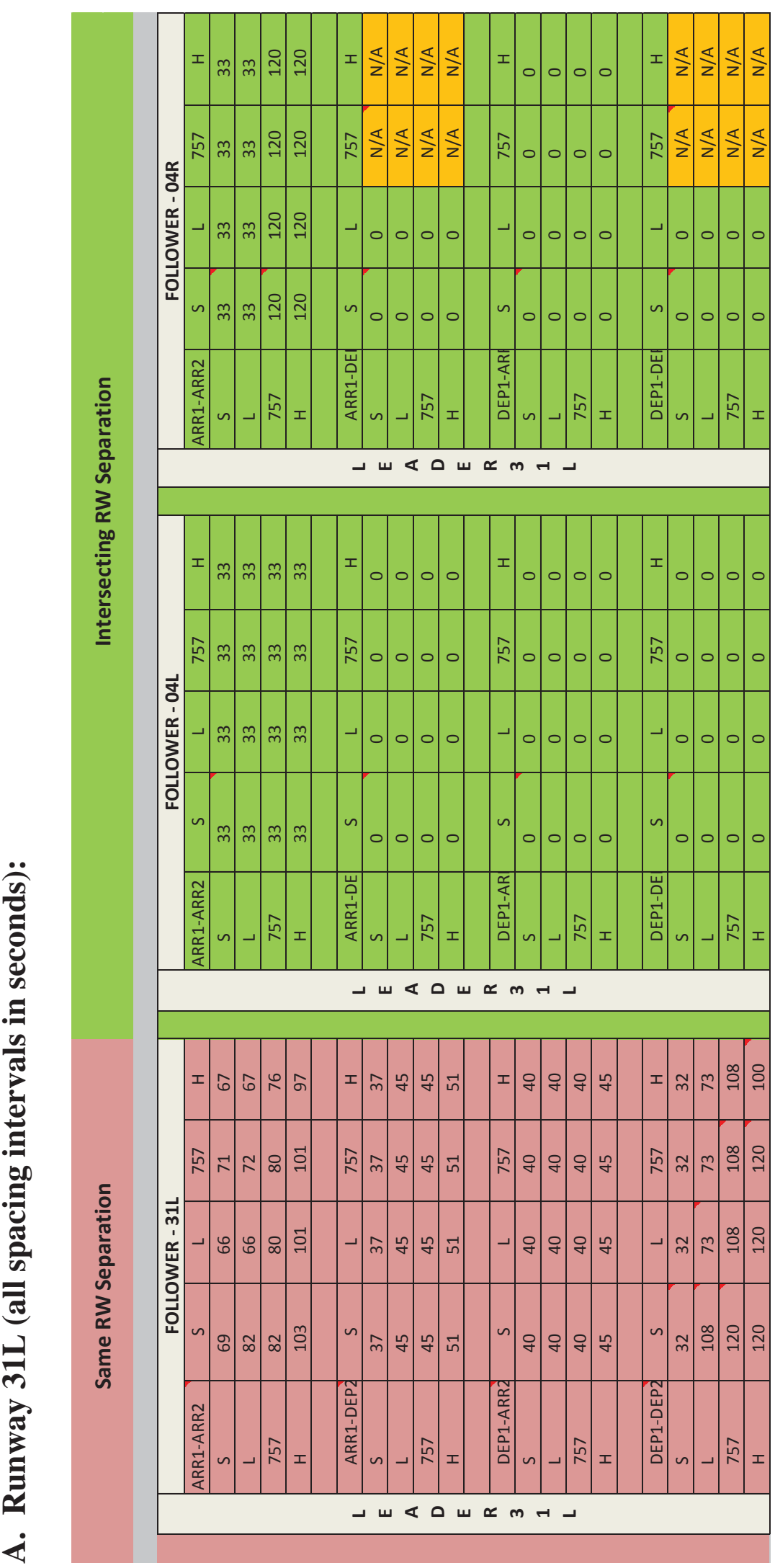




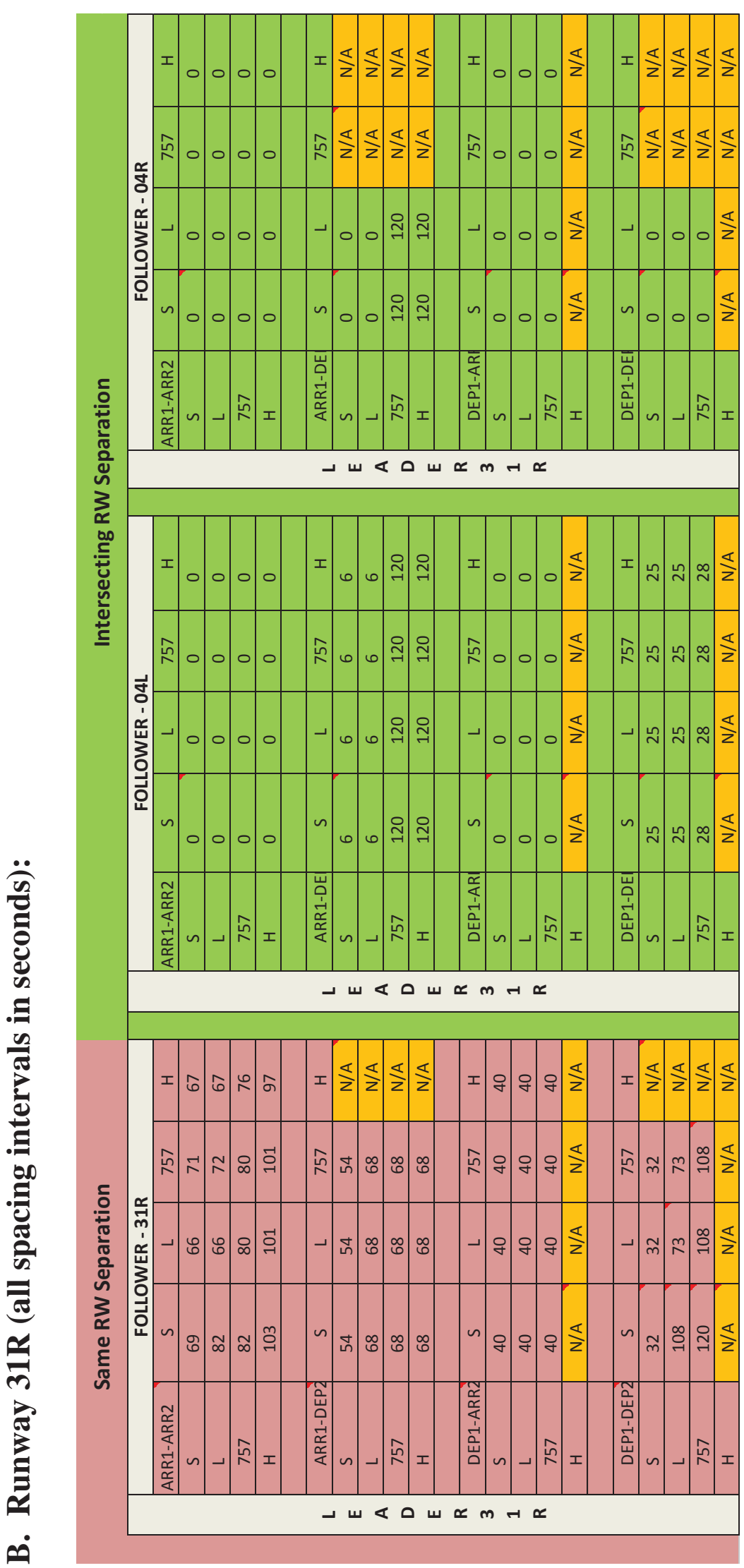




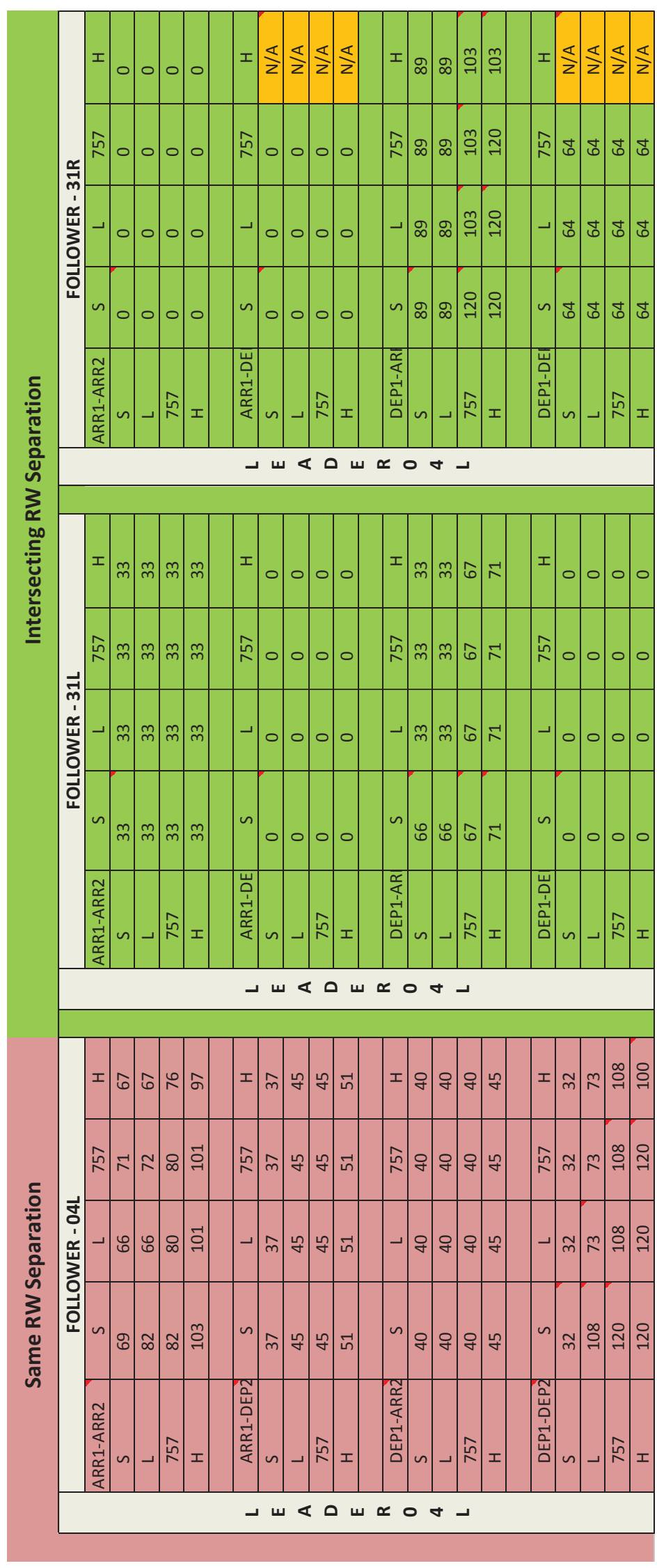

15

American Institute of Aeronautics and Astronautics 

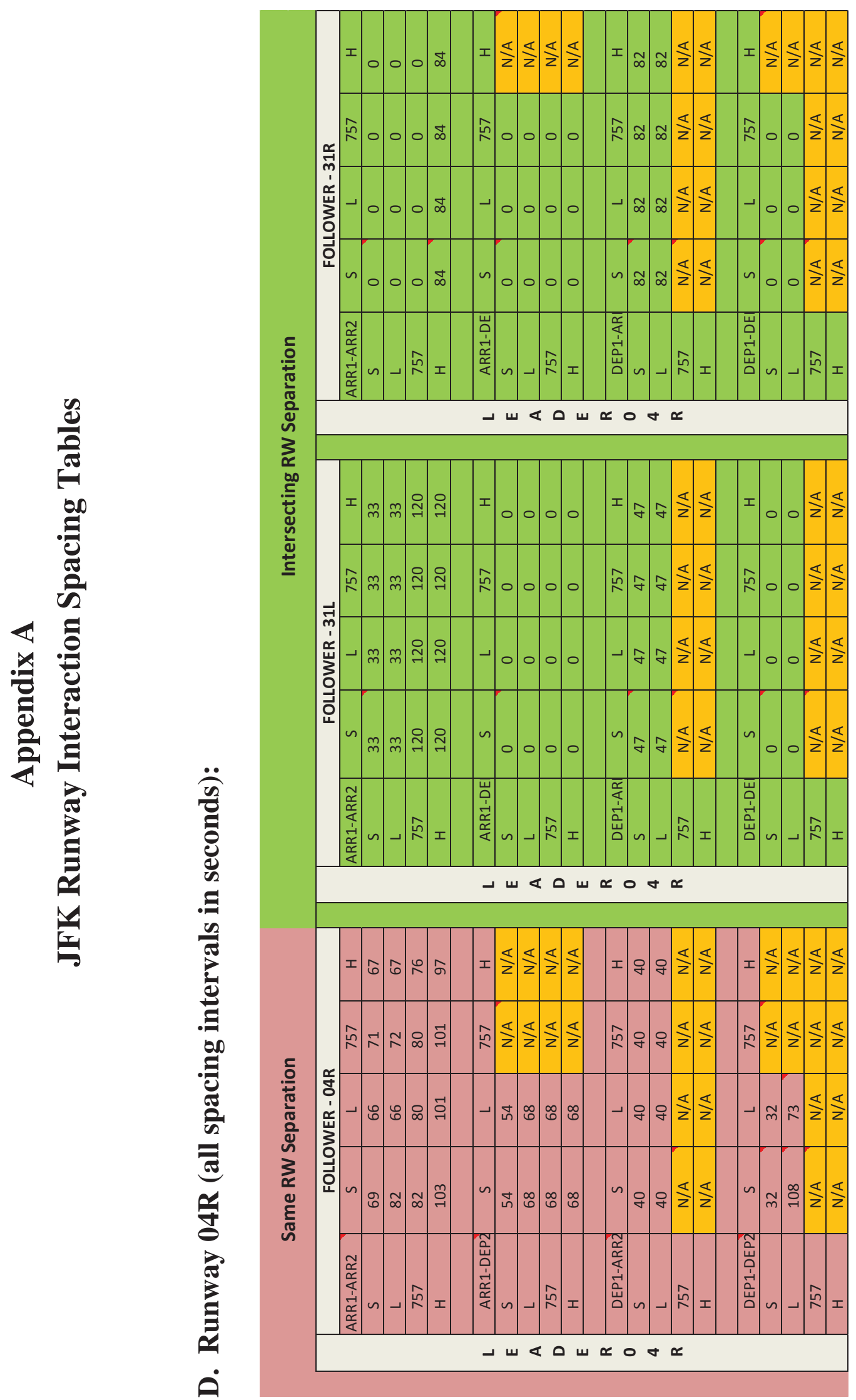

16

American Institute of Aeronautics and Astronautics 
Appendix B

Bases for JFK Runway Interaction Spacing Tables Intervals

A. Runway 31L: Spacing Interval Operational Assumptions:

\begin{tabular}{|c|c|c|c|}
\hline $\begin{array}{ll}\mathrm{RW}-1 \\
31 \mathrm{~L}\end{array}$ & $\begin{array}{c}31 \mathrm{~L} \\
\text { (Same RW) }\end{array}$ & $\begin{array}{c}04 \mathrm{~L} \\
\text { (Intersecting RW) }\end{array}$ & $\begin{array}{c}\text { 04R } \\
\text { (Intersecting RW) }\end{array}$ \\
\hline Arr/Arr - & $\begin{array}{l}\text { Based on the lowest same- } \\
\text { runway inter-arrival time } \\
\text { intervals from Ref's } 1-3\end{array}$ & $\begin{array}{l}\text { 31L Arr clear of intersection } \\
\text { prior to 04L Arr at twice the } \\
\text { Decision Height (i.e. } 200 \\
\text { HAT) along } 3 \text { dgr GS at } 140 \\
\text { kt Approach Speed } \\
\text { - Assumes 04L ARR touches } \\
\text { down prior to intersection } \\
\text { (3700+ ft to intersection) }\end{array}$ & $\begin{array}{l}\text { - 31L ARR clear of } \\
\text { intersection prior to 04R } \\
\text { ARR at twice the Decision } \\
\text { Height (i.e. } 200 \text { HAT) along } \\
3 \text { dgr GS at } 140 \text { kt Approach } \\
\text { Speed } \\
\text { - } 7110.65 U \text {; Fig. 3-10-10; } \\
\text { Wake turbulence constraint } \\
\text { (**NOTE** Assumes wake } \\
\text { turbulence not a constraint for } \\
\text { Small or Large category lead } \\
\text { A/C) }\end{array}$ \\
\hline Arr/Dep - & $\begin{array}{l}\text { Based on ROT with } 30 \\
\text { degree high-speed RW } \\
\text { exits from Ref's 4-6 }\end{array}$ & $\begin{array}{l}\text { 04L Dep commences once } \\
\text { 31L Arr clear of intersection } \\
\text { (**NOTE** 31L displaced } \\
\text { threshold beyond 04L } \\
\text { intersection) }\end{array}$ & $\begin{array}{ll} & \text { 04R Heavy \& B757 } \\
\text { Departures prohibited due to } \\
\text { RW Length } \\
\text { - } \\
\text { 04R Small \& Large } \\
\text { Departures commence take- } \\
\text { off roll after 31L Arr crosses } \\
\text { over 04R }\end{array}$ \\
\hline Dep/Arr - & $\begin{array}{l}\text { Based on JO 7110.65U; } \\
\text { departure airborne \& > } \\
6000 \text { Ft from Arr crossing } \\
\text { the threshold }\end{array}$ & $\begin{array}{l}\text { Assumes 31L intersection } \\
\text { departure commences beyond } \\
\text { 04L intersection and 04L Arr } \\
\text { touches down prior to 31L } \\
\text { intersection (i.e. - no jet blast } \\
\text { constraint) } \\
\end{array}$ & $\begin{array}{l}\text { - 31L Departures assumed to } \\
\text { begin beyond 04L } \\
\text { intersection, therefore jet } \\
\text { blast is not a concern (no } \\
\text { constraint) }\end{array}$ \\
\hline Dep/Dep - & $\begin{array}{l}\text { Based on JO 7110.65U; } \\
\text { requires } 2 \text { minutes for } \\
\text { DEP2 following 757/Hvy, } \\
\text { but use radar separation per } \\
\text { 5-5-4 for all cases when } \\
\text { required interval is less } \\
\text { than } 2 \text { min. (assumes } \\
\text { LUAW \& Anticipating } \\
\text { Separation) }\end{array}$ & $\begin{array}{l}\text { Assumes 31L intersection } \\
\text { departure commences beyond } \\
\text { 04L intersection and 04L Dep } \\
\text { not airborne prior to 31L } \\
\text { intersection (i.e. - Jet Blast } \\
\text { not an issue) }\end{array}$ & $\begin{array}{l}\text { Assume 04R Heavy \& B757 } \\
\text { Departures prohibited due to } \\
\text { RW length } \\
\text { - 31L Departures assumed to } \\
\text { begin beyond 04L } \\
\text { intersection, therefore jet } \\
\text { blast is not a concern (no } \\
\text { constraint) }\end{array}$ \\
\hline
\end{tabular}




\section{Appendix B}

\section{Bases for JFK Runway Interaction Spacing Tables Intervals}

B. Runway 31R: Spacing Interval Operational Assumptions:

\begin{tabular}{|c|c|c|c|}
\hline RW-1 $\mathrm{RW-2}$ & $\begin{array}{c}31 \mathrm{R} \\
\text { (Same RW) }\end{array}$ & $\begin{array}{c}\text { 04L } \\
\text { (Intersecting RW) }\end{array}$ & $\begin{array}{c}\text { 04R } \\
\text { (Intersecting RW) }\end{array}$ \\
\hline Arr/Arr - & - Same as 31L & $\begin{array}{l}\text { - No interaction assuming } \\
\text { LAHSO for 04L ARR }\end{array}$ & $\begin{array}{l}\text { - 31R ARR clear of } \\
\text { intersection prior to 04R } \\
\text { ARR crossing RW threshold }\end{array}$ \\
\hline Arr/Dep - & 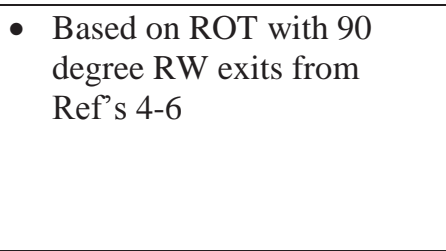 & $\begin{array}{l}\text { - 04L Dep commences once } \\
\text { 31R ARR clear of } \\
\text { intersection (31R threshold } \\
\text { prior to 04L intersection) }\end{array}$ & $\begin{array}{l}\text { - } 757 \text { \& Heavy class aircraft } \\
\text { DEP prohibited from 04R } \\
\text { (too short) } \\
\text { - } 31 \mathrm{R} \text { ARR clear of } \\
\text { intersection prior to 04R DEP } \\
\text { starting take-off roll }\end{array}$ \\
\hline Dep/Arr - & $\begin{array}{l}\text { - Same as 31L except Heavy } \\
\text { departures prohibited on } \\
\text { 31R }\end{array}$ & $\begin{array}{l}\text { - Heavy class DEP assumed } \\
\text { prohibited from 31R } \\
\text { - No interaction assuming } \\
\text { LAHSO for 04L ARR for } \\
\text { other weight classes }\end{array}$ & $\begin{array}{l}\text { - Heavy class DEP prohibited } \\
\text { from 31R } \\
\text { - Jet Blast from 31R DEP not } \\
\text { an issue for 04R ARR }\end{array}$ \\
\hline Dep/Dep - & - Same as 31L & $\begin{array}{l}\text { Heavy class DEP assumed } \\
\text { prohibited from 31R } \\
\text { Based on distance time } \\
\text { profiles for take-off roll for } \\
\text { 31R DEP clear of intersection } \\
\text { prior to 04L DEP start of } \\
\text { take-off roll. }\end{array}$ & $\begin{array}{ll}\text { - } & \text { 04R Heavy \& B757 DEP } \\
\text { prohibited } \\
\text { - } \\
\text { 31R Heavy DEP prohibited } \\
\text { - Jet Blast from 31R DEP not } \\
\text { an issue for 04R DEP } \\
\text { (assume Small \& Large } \\
\text { category DEP rotate prior to } \\
\text { 31R intersection and fly } \\
\text { above any jet blast) }\end{array}$ \\
\hline
\end{tabular}




\section{Appendix B}

\section{Bases for JFK Runway Interaction Spacing Tables Intervals}

\section{Runway 04L: Spacing Interval Operational Assumptions:}

\begin{tabular}{|c|c|c|c|}
\hline RW-1 & $\begin{array}{c}\text { 04L } \\
\text { (Same RW) }\end{array}$ & $\begin{array}{c}\text { 31L } \\
\text { (Intersecting RW) }\end{array}$ & $\begin{array}{c}31 \mathrm{R} \\
\text { (Intersecting RW) }\end{array}$ \\
\hline Arr/Arr - & - Same as 31L & $\begin{array}{l}\text { - When 31L Arr is at twice the } \\
\text { DH ( i.e. -2x the } 200 \text { HAT or } \\
400 \text { ') along its } 3 \text { dgr GS, @ } \\
140 \text { kt - 31L pilot can } \\
\text { determine the 04L Arr has } \\
\text { landed \& will roll clear of } \\
\text { intersection prior to the 31L } \\
\text { Arr crossing intersection. } \\
\text { **NOTE** assumes 04L } \\
\text { ARR touches down prior to } \\
\text { intersection, nominally } \\
\text { @1000 - } 1500 \mathrm{ft} . \mathrm{fr} . \text { its } \\
\text { threshlold. }\end{array}$ & $\begin{array}{l}\text { - Assume LAHSO with LDA } \\
\text { for 04L being 10,400' or } \\
\text { more from 31R intersection } \\
\text { (no constraint) }\end{array}$ \\
\hline Arr/Dep - & $\begin{array}{l}\text { - } \quad \text { Same as 31L } \\
\text { - Although 04L currently has } \\
\text { no } 30 \text { degree high speed } \\
\text { exits, there is room for one } \\
\text { or more to the SE }\end{array}$ & $\begin{array}{l}\text { - 31L departures begin beyond } \\
\text { intersection AND 04L } \\
\text { arrivals land prior to } \\
\text { intersection so jet blast is not } \\
\text { an issue thus, the runways } \\
\text { operated independently }\end{array}$ & 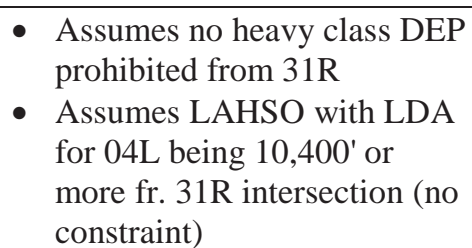 \\
\hline Dep/Arr - & - Same as 31L & $\begin{array}{l}\text { - } 04 \text { L DEP clear of intersection } \\
\text { prior to 31L Arr at twice the } \\
200 \text { HAT DH (i.e.- 400') } \\
\text { along } 3 \text { dgr GS @ } 140 \text { kt } \\
\text { Appr. Spd. }\end{array}$ & $\begin{array}{l}\text { For Lead aircraft of Small \& } \\
\text { Large wake category: 04L } \\
\text { DEP clear of intersection } \\
\text { prior to 31R Arr at twice the } \\
200 \text { HAT DH (i.e.- 400') } \\
\text { along } 3 \text { dgr GS @ } 140 \text { kt } \\
\text { Appr. Spd } \\
\text { - For Lead aircraft of } 757 \text { \& } \\
\text { Heavy wake category: see } \\
\text { Fig. 3-10-10 in JO 7110-65U; } \\
\text { Use lesser of 120s or radar } \\
\text { separation minima }\end{array}$ \\
\hline Dep/Dep - & - Same as 31L & $\begin{array}{l}\text { Assuming 31L departures } \\
\text { start beyond the 04L } \\
\text { intersection and 04L } \\
\text { departures are not airborne } \\
\text { prior to the 31L intersection, } \\
\text { then no interaction }\end{array}$ & $\begin{array}{l}\text { - } 31 \mathrm{R} \text { Heavy DEP prohibited } \\
\text { - } 04 \mathrm{~L} \text { Dep Clear of RW end } \\
\text { prior to 31R Dep starting T/O } \\
\text { roll }\end{array}$ \\
\hline
\end{tabular}




\section{Appendix B}

\section{Bases for JFK Runway Interaction Spacing Tables Intervals}

\section{Runway 04R: Spacing Interval Operational Assumptions:}

\begin{tabular}{|c|c|c|c|}
\hline RW-1 & $\begin{array}{c}\text { 04R } \\
\text { (Same RW) }\end{array}$ & $\begin{array}{c}31 \mathrm{~L} \\
\text { (Intersecting RW) }\end{array}$ & $\begin{array}{c}\text { 31R } \\
\text { (Intersecting RW) }\end{array}$ \\
\hline Arr/Arr - & - $\quad$ Same as 31L & $\begin{array}{l}\text { 04R Arr clear of intersection } \\
\text { prior to 31L Arr at 2x the DH } \\
\text { (i.e. -2x the } 200 \text { HAT DH } \\
\text { along } 3 \text { dgr GS, } 140 \text { kt Appr. } \\
\text { Spd.) **NOTE** 31L offset } \\
\text { threshold keeps 31L Arr } \\
\text { above 04R trajectory, } \\
\text { eliminating wake encounter } \\
\text { concerns }\end{array}$ & 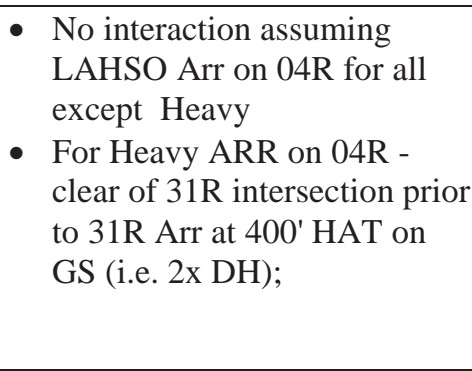 \\
\hline Arr/Dep - & $\begin{array}{l}\text { - Assume no } 757 \text { or Heavy } \\
\text { DEP from 04R } \\
\text { Based on ROT with } 90 \\
\text { degree RW exits from } \\
\text { Ref's 4-6 }\end{array}$ & $\begin{array}{l}\text { - 31L Dep begins ahead of 04L } \\
\text { intersection so no Jet Blast } \\
\text { concerns }\end{array}$ & $\begin{array}{l}\text { - } \text { Assumes Heavy DEP } \\
\text { prohibited from 31R } \\
\text { - Jet Blast from 31R DEP not } \\
\text { an issue for 04R ARR (no } \\
\text { constraint) } \\
\end{array}$ \\
\hline Dep/Arr - & $\begin{array}{l}\text { - Assume no } 757 \text { or Heavy } \\
\text { DEP from 04R } \\
\text { - See JO 7110.65U Req't of } \\
\text { airborne \& } 6000 \text { feet when } \\
\text { trailing aircraft crosses } \\
\text { landing threshold }\end{array}$ & $\begin{array}{l}\text { - Assume no } 757 \text { or Heavy } \\
\text { DEP from 04R } \\
\text { 04R DEP clear of intersection } \\
\text { prior to 31L Arr at twice the } \\
200 \text { HAT DH (i.e.- } 400 \text { ') } \\
\text { along } 3 \text { dgr GS @ } 140 \text { kt } \\
\text { Approach Speed } \\
\end{array}$ & $\begin{array}{l}\text { - Assume no } 757 \text { or Heavy } \\
\text { DEP from 04R } \\
\text { 04R DEP clear of intersection } \\
\text { prior to 31R ARR at twice the } \\
200 \text { HAT DH (i.e.- } 400 \text { ') } \\
\text { along } 3 \text { dgr GS @ } 140 \mathrm{kt} \\
\text { Approach Speed }\end{array}$ \\
\hline Dep/Dep - & $\begin{array}{l}\text { - Assume no } 757 \text { or Heavy } \\
\text { DEP from 04R } \\
\text { - Same as 31L otherwise }\end{array}$ & $\begin{array}{l}\text { - Assume no } 757 \text { or Heavy } \\
\text { DEP from 04R } \\
\text { - 31L Dep begins ahead of 04L } \\
\text { intersection so no Jet Blast } \\
\text { concerns }\end{array}$ & $\begin{array}{l}\text { - Assume no Heavy DEP from } \\
\text { 31R } \\
\text { - Assume no 757 or Heavy } \\
\text { DEP from 04R } \\
\text { - } \text { Jet Blast from 31R DEP not } \\
\text { an issue for 04R DEP except } \\
\text { when 31R DEP is 757, but } \\
\text { assume 04R DEP rotates \& } \\
\text { flies above 757 Jet Blast }\end{array}$ \\
\hline
\end{tabular}




\section{References}

${ }^{1}$ Kumar, V. and Lance Sherry. "Airport Throughput Capacity Limits for Damand Management Planning." Integrated Communications, Navigation and Surveillance Conference, 2009. ICNS '09. Fairfax, VA: Center for Air Transportation Systems Research, George Mason University, 2009

${ }^{2}$ Babak Ghalebsaz-Jeddi, George L. Donohue, John F. Shortle. "A Statistical Analysis of the Aircraft Landing Process." Journal of Industrial and Systems Engineering, Fall 2009: Vol. 3, No. 3, pp 152-169

${ }^{3}$ FAA. AC: 150/5060-5; Airport Capacity and Delay. Washington, D.C.: FAA; Office of Airport Standards, September 23, 1983.

${ }^{4}$ Monk, Hellen. "Helen's Rules of Thumb." FAA Technical Center Capacity Seminar. Atlantic City, NJ: FAA, May 24, 2006

${ }^{5}$ Ballin, M.G. and Heinz Erzberger. "An Analysis of Landing Rates and Separations at the Dallas/Fort Worth International Airport." NASA Technical Memorandum 110397. Moffett Field, CA: NASA, July 1996

${ }^{6}$ Andrews, J.W. and John E. Robinson III. "Radar-Based Analysis of the Efficiency of Runway Use." AIAA Guidance, Navigation \& Control. Montreal, Quebec: AIAA-2001-4359, 2001

${ }^{7}$ Mundra, A. D. "A Description of Air Traffic Control in the Current Terminal Airspace Environment." Mitre MTR-88W00167. McLean, VA: Mitre, March 1989

${ }^{8}$ LeBron, J. E. "Estimates of Potential Increases in Airport Capacity Through ATC System Improvements in the Airport and Terminal Areas." Mitre - MTR-87W203. McLean, VA: Mitre, October 1987

${ }^{9}$ Weiss, W. E. and J. N. Barrer. "Analysis of Runway Occupancy Time and Separation Data Collected at LaGuardia, Boston and Newark Airports." Mitre - MTR-84W228. McLean, VA, December 1984

10 Thompson, S.D. Terminal Area Separation Standards: Historical Development, Current Standards, and Processes for Change. Lexington, MA: Lincoln Laboratory; Project Report ATC-258, 1997

11 PB Americas, Inc., Landrum \& Brown. FAA Regional Air Service Demad Study. New York: FAA, and Deleware Valley Regional Planning Commission, 2007

${ }^{12}$ Kumar, V., Sherry, L., and Kicinger, R., " Runway occupancy time extraction and analysis using surface track data," Transportation Research Board 89th Annual Meeting, Washington DC, January 2010.

${ }^{13}$ Trani, A. A., Cao, J., Kim, B. J., Gu, X., Zhong, C. Y., and Tarrago-Trani, M. T., "Flight simulations of high speed runway exits," Virginia Polytechnic Institute and State University, Department of Civil Engineering, Transportation Systems Laboratory, Blacksburg, VA, 1996. 